\title{
“PELO ESPAÇO” NA VIA DE DOREEN MASSEY: UMA ANÁLISE PEDAGÓGICA DE "MATERIAL GEOGRAPHIES"
}

\author{
“FOR SPACE” IN DOREEN MASSEY'S WAY: A PEDAGOGICAL ANALYSIS OF “MATERIAL \\ GEOGRAPHIES"
}

\author{
Ana Angelita da Rocha * \\ *Professora do Departamento de Didática da Faculdade de Educação da UFRJ - Bolsista CNPq Pós Doutorado Júnior - \\ ana angelita@ufrj.br.
}

Recebido em 08/08/2018. Aceito para publicação em 25/08/2018.

Versão online publicada em 20/11/2018 (http://seer.ufrgs.br/paraonde)

\begin{abstract}
Resumo: A questão central deste estudo busca refletir sobre o aspecto pedagógico na extensa produção bibliográfica da geógrafa britânica Doreen Massey. 0 presente estudo se ocupará da análise de conteúdo do capítulo Geographies of solidarities, inserido no material pedagógico do curso Material Geographies - a world in the making. Tal publicação, editada pela Open University em 2008, trata-se de material pedagógico adotado para curso da mesma instituição de educação a distância (EAD) e que ao mesmo tempo difunde tendências teóricas dirigidas pela Open Space Research. Tal intuito investe na análise da produção bibliográfica da autora, com atenção focada nos títulos dirigidos aos cursos ministrados ou organizados por ela na década de 1990, na Open University (em Milton Keynes, Reino Unido). Esta aproximação com esses trabalhos - ainda sem tradução para o português - procura inventariar os aspectos pedagógicos de Doreen Massey e seus possíveis desdobramentos para o currículo da Geografia Escolar no Brasil.
\end{abstract}

Palavras-chave: espaço, Doreen Massey, Geografia Escolar.

Abstract: The aim of this article seeks to reflect on the pedagogical aspect in the extensive bibliographic production of the British Geography Doreen Massey. The current study deals with the content analysis of the chapter Geographies of solidarities, inserted in the pedagogical material of the course Material Geographies - a world in the making. This paperback, edited by Open University in 2008, is a pedagogical material adopted by the course of the same institution of distance education and at the same time it diffuses theoretical tendencies directed by Open Space Research. Our aim seeks to analyse the Bibliography of the author and to focuses on the titles directed by courses taught or organized by Massey in the 1990's, at the Open University (in Milton Keynes, UK). This approach to these issues - still without a Portuguese translation -look forward a file Doreen Massey's pedagogical ideas and how it tie in the School Geography curriculum in Brazil.

Key-words: space, Doreen Massey, Geography Education.

\section{Introdução}

O presente estudo se ocupará da análise de conteúdo do capítulo Geographies of solidarities, inserido no material pedagógico do curso Material Geographies - a world in the making. Tal publicação, editada pela Open University em 2008, trata-se de material pedagógico adotado para curso da mesma instituição de educação a distância e que ao mesmo tempo difunde tendências teóricas dirigidas pela Open Space Research. Ao vislumbrarmos as operações didáticas eleitas por Doreen Massey, temos a intenção de analisar a relação entre epistemologia da geografia e demandas curriculares, que provocam mudanças propositivas na Geografia Escolar. Para tanto, essa associação entre ciência geográfica e saberes pedagógicos pode oferecer elementos que induzem às inovações curriculares no campo da Geografia Escolar.

Para além da lógica do espaço como superfície, ou no dizer de Massey como recipientes de 
identidades fixas, vemos como viável a adoção da pauta da multiplicidade como princípio de interpretação do espaço, nos currículos progressistas. Deste modo, compreendemos que quando abordamos a interpretação espacial com o enfoque no aprendizado espacial, isentando os conceitos formais, abordamos, sem dúvida, domínios espaciais, que tanto procuram fundar sentidos de dimensão, extensão e continuidade (lógicas zonais) sobre o espaço, quanto aqueles ocupados com os fluxos e as redes, os movimentos inteligíveis pela chamada lógica reticular (HAESBAERT, 2006).

No capítulo objeto de nossa interpretação, Doreen Massey articula a densidade teórica de espaço à análise empírica de fenômenos, operando com ferramentas didáticas como a comparação, a descrição e o estudo de caso. A dimensão metodológica desse estudo focará no inventário dos recursos imagéticos e pedagógicos adotados por Doreen Massey no referente capítulo, especialmente quando a autora oferece uma transposição didática de seu conceito de espaço. Cabe sinalizar que a face pedagógica de Doreen Massey não tem sido explorada em estudos da Geografia escolar em língua portuguesa. Tal fato evidencia a pertinência do presente estudo para o debate sobre o ensino dessa disciplina no Brasil, por ora desafiada pelos retrocessos das políticas curriculares.

O objetivo central deste artigo deriva do projeto "Lições de Doreen Massey" que busca, a partir da revisão bibliográfica e da análise do impacto teórico da autora, entender as estratégias epistemológicas para a compreensão espacial na escola. A dimensão curricular da análise está na interface entre o conhecimento geográfico e a teoria curricular, considerando autores da dimensão crítica como Paulo Freire (1967). Essas breves considerações de pressupor o espaço como conceito político permite explorar a conexão entre a epistemologia da Geografia e o ensino de geografia escolar. Isto porque o diálogo com essa autora exige a coerência, ou seja, a vigilância quanto à produção de reflexões que estejam desconfiadas das fundamentações essencialistas que predominam o ensino da disciplina.

\section{Geografias das Solidariedades: um conteúdo que potencializa o Currículo e a Geografia}

Nothing ever becomes real till experienced - even a proverb is no proverb until your life has illustrated it.

John Keats

Esta seção tem o foco na descrição das estratégias adotadas por Doreen Massey ao eleger a Geografia das Solidariedades (tradução livre) como conteúdo. Trata-se do sétimo capítulo do livro Material Geographies - a World in the Making, organizado pela autora em parceria com Nigel Clark e Philip Sarre (2008). O livro, somado ao volume Geographies of Globalization: a demanding world (BARRET et.al., 2008), integra o material do curso Living in a Globalised World, oferecido pela Open University, com o objetivo de explorar questões chaves da globalização. Os versos que abrem a seção tomam de empréstimo do poeta inglês a centralidade da experiência para inteligibilidade da vida, algo muito próximo à compreensão espacial desenvolvida por Doreen Massey. Logo, os seus textos didáticos são coerentes com a premissa do espaço como experiência.

De modo geral, ao examinar os processos espaciais, particularmente, a partir da perspectiva da Geografia Econômica, o livro editado por Massey e seus parceiros, indica o necessário método de "pensar geograficamente" para compreensão das relações políticas e sociais que configuram o fenômeno da globalização. Interessante observar que o Curso Living in a Globalised World é produto de um esforço coletivo entre pesquisadores para problematizar a natureza da globalização. Por ser, logo, material e recurso de um curso a distância, a escrita é moldada com inteligibilidade didática, cuja clareza e riqueza de imagens e dados indicam a qualidade pedagógica do texto.

ParaOnde!?, Porto Alegre, v.10, n.2, p.85-95, 2018. Edição Especial com artigos publicados originalmente na XII ENANPEGE http://seer.ufrgs.br/paraonde 


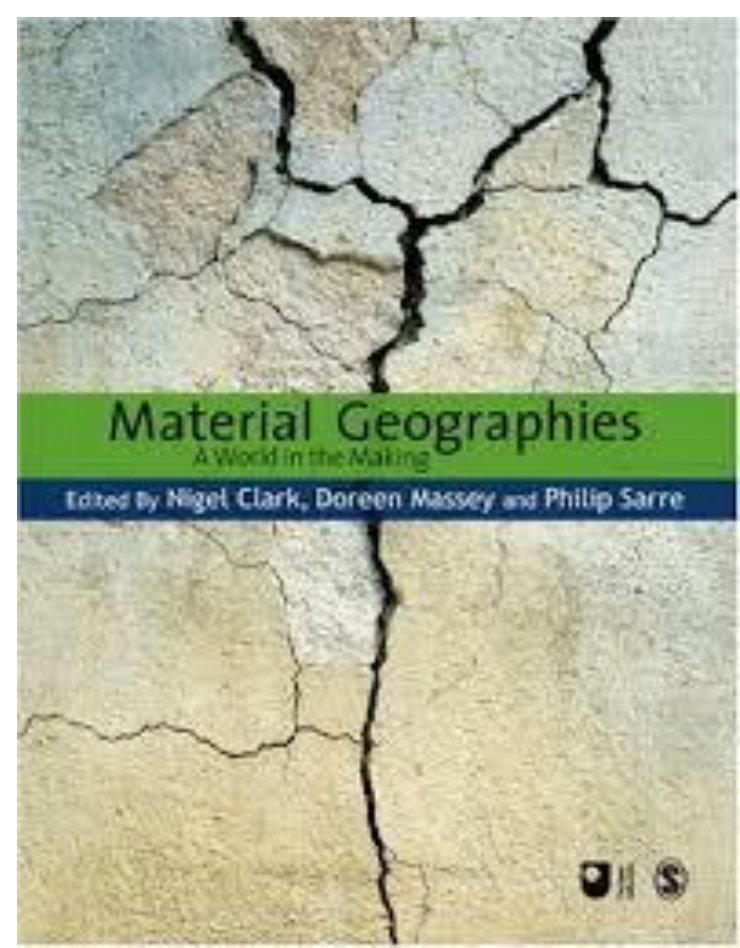

Figura 1: capa do livro, edição 2008

Interessante observar que o volume Material Geographies - a World in making, é um livro ocupado com a dinâmica da globalização, com o esforço de superar a dicotomia sociedade natureza. Os seus organizadores afirmam esta intencionalidade no próprio título ao indicarem que "Embora pareça que vivemos em uma realidade pronta, nosso mundo está constantemente sendo feito e refeito. Ao escolher este título, estamos tentando chegar a um argumento muito particular [relação sociedade e natureza], que é o tema dominante do livro." (MASSEY \& CLARK, 2008:1).

A preocupação com a produção do mundo se faz na análise integradora dos movimentos físicos e humanos, com o foco nos sujeitos e fatores responsáveis pela globalização. Portanto, para os autores, a compreensão processual se faz nos estudos de caso, considerando especialmente os conceitos de território e fluxos:

Um dos argumentos centrais deste livro é que essa interação constante entre território e fluxo é um aspecto crucial de um mundo globalizado. Tanto o território quanto o fluxo podem ocorrer em muitas formas. Um "fluxo" pode ser a transmissão instantânea de finanças, ou os movimentos físicos maciços de bens e commodities negociados. Ou pode ser o movimento das correntes oceânicas. E, no atual período de mudanças climáticas, as migrações de plantas e animais estão acontecendo de novo, como, por exemplo, algumas espécies encontram dificuldades cada vez mais em sobreviver nas ilhas do Reino Unido, enquantro outras chegam. Todos esses movimentos que nos referimos aqui são o que entendemos por fluxos. (MASSEY\&CLARK, 2008: 3).

Nos estudos de caso, como recursos pedagógicos, há o interesse na análise de dinâmica da natureza associada às práticas sociais, considerando o desenvolvimento da complexidade em múltiplas escalas. Por esta razão, os casos e exemplos são apresentados como resultantes de uma geometria de poder, dos processos desiguais do capital.

O sétimo capítulo do volume traz como título Geografias das solidariedades. É organizado em seis subseções, duas leituras complementares, sete atividades e oito recursos visuais, distribuídos em quarenta e oito páginas.

Interessante observar algumas considerações a respeito da natureza didática dos materiais impressos para a educação a distância. A totalidade da coleção e do curso é elaborada por pesquisadores que farão transposição didática de seus objetos. Estamos de acordo com a noção de que 
livro didático é um gênero textual. 0 livro dedicado exclusivamente ao EAD obedece às características específicas, para atender a modalidade. Por esta razão, é um gênero textual que combina recursos voltados para a interatividade com o leitor, sem descuidar-se do rigor acadêmico, por conta do nível de formação.

Em outras palavras, há a necessidade da contextualização dos conteúdos, da experiência cotidiana, para garantir a interatividade e a dialogicidade do texto. Por isso, uma das marcas textuais é a reiteração, há diferentes recursos que enfatizam a síntese e a revisão dos conteúdos. Portanto, podemos identificar no capítulo de Doreen Massey as seguintes operações didáticas: a descrição, a comparação e a enumeração dos fatores e das causas da dinâmica espacial. Por esta razão, identificamos o estudo de caso como método de aprendizagem privilegiado pela autora em suas obras didáticas.

No capítulo Geografias das Solidariedades, podemos identificar a potência da ambiguidade entre a pesquisadora e autora didática. 0 que permite a produção de uma linguagem multimoldal (verbal e não verbal) que viabiliza o ato de pedagogizar a sua interpretação do espaço. Massey sublinha as organizações populares na seção "Another world is possible" para vislumbrar conteúdos geográficos dos conflitos políticos e territoriais, a partir de sua percepção do espaço como múltiplo.

Massey narra os movimentos de resistência, a partir dos casos de La Coordenadora, na Bolívia, e do Exército Zapatista, no México. Ela os narra, como movimentos de esperança (2008:318). Os exercícios e as imagens são recursos sublinhados para evidenciar o protagonismo dos movimentos sociais para definir a concepção dela de espaço como encontro, como coetaneidade, desenvolvida em trabalhos como "Pelo Espaço" (2008).

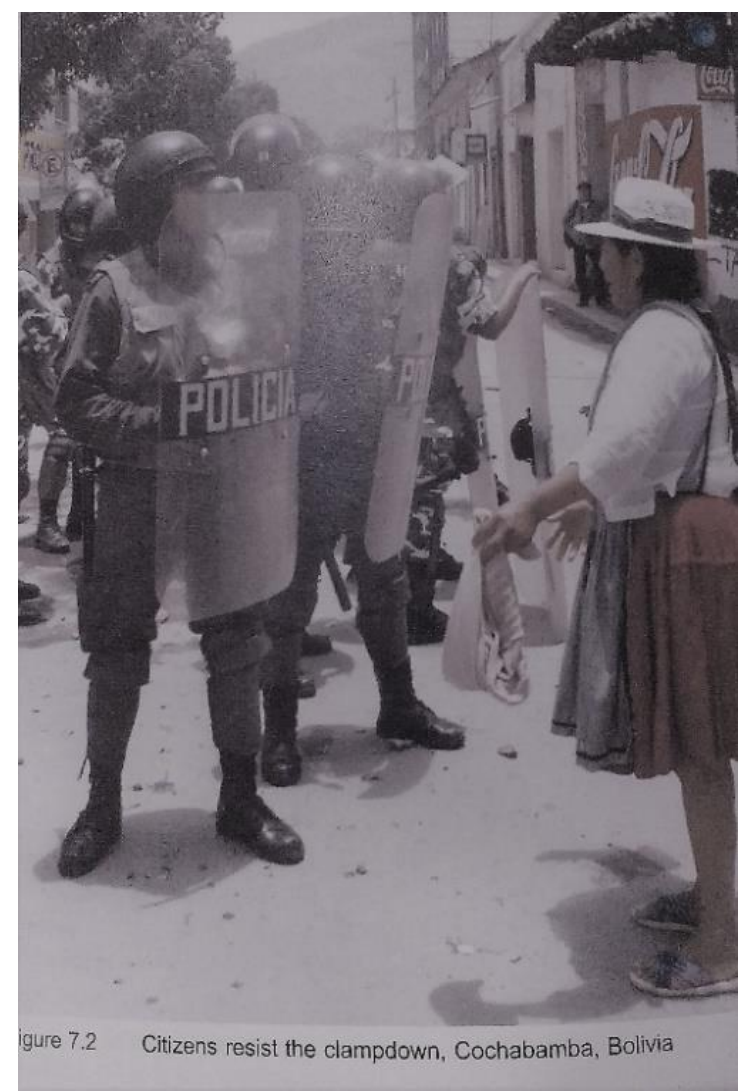

Figura 2: imagem extraída da seção Another world is possible, que retrata a emergência de novos movimentos sociais na América Latina (MASSEY, 2008, P. 316). 
Massey, ao desenvolver seus argumentos conceituais e narrar esses casos, frequentemente interroga seu leitor, o interpela a comparar a experiência vivida ao dos personagens narrados: "Como você pode argumentar contra a crescente interligação do mundo?" (2008:320). Na contextualização do debate em que se insere tal interrogação ao seu leitor, Massey desenvolve associadamente dois argumentos. O primeiro trata da descrição e, ao mesmo tempo, dos questionamentos das forças externas da Globalização. 0 segundo diz respeito à análise crítica das consequências, especialmente, da homogeneização espacial, por vezes provocada pelos processos inseridos na globalização. Não por acaso, ela sustenta seus argumentos ao empregar os conceitos de fluxo e território. Para ilustrar tal apreciação didática, convém a interpretação da seguinte proposta de atividade:
Atividade 7.2
Leia o último parágrafo novamente e reformule esse sentimento em termos de conceitos de território e fluxo. Em seguida, aproveite o que aprendemos até agora sobre territórios e fluxos para refutar essa crítica. (Você encontrará sugestões para a resposta ao longo desta seção.)
* Último parágrafo
Uma das maneiras em que as pessoas experimentam mais diretamente "o mundo globalizado" é através do impacto que ele tem em suas vidas diárias. Embora este impacto possa ser enriquecedor, também pode ser perturbador. Há, por exemplo, queixas constantes sobre a invasão e mudança dos lugares pelas "forças externas" da globalização. É o tipo de sentimento que, de fato, encoraja a defesa de lugares existentes contra "o estrangeiro". (2008: 321, tradução livre)

Observem que a autora oferece uma interação pedagógica com o seu leitor para reinterpretar uma sentença, que poderia servir como premissa para discursos conservadores. 0 argumento central é descontruir um senso comum que antagoniza o lugar à globalização. Nesse exercício, ela articula sua discussão sobre "os sentidos globais de lugar", incitando seu leitor a fazer uma ressignificação do cotidiano vivido. Esse tipo de interpelação ao leitor ocorre em diferentes momentos do texto principal.

Além disso, a questão em tela é precedida pela definição de "novos movimentos sociais", em boxe destacado no texto principal. Importante ressaltar que nesse gênero textual há a valorização de boxes, como uma caixa de diálogo e de esclarecimento com a função didática na aprendizagem a distância. Importa observar que isto é uma ferramenta recorrente do texto. Outro é o boxe de síntese de conteúdos, em que os autores se valem da reiteração como operação didática. Na aprendizagem a distância, a reiteração é um recurso em que os autores se apoiam para o esclarecimento ou para o desenvolvimento do argumento, especialmente nos capítulos que objetivam o emprego conceitual.

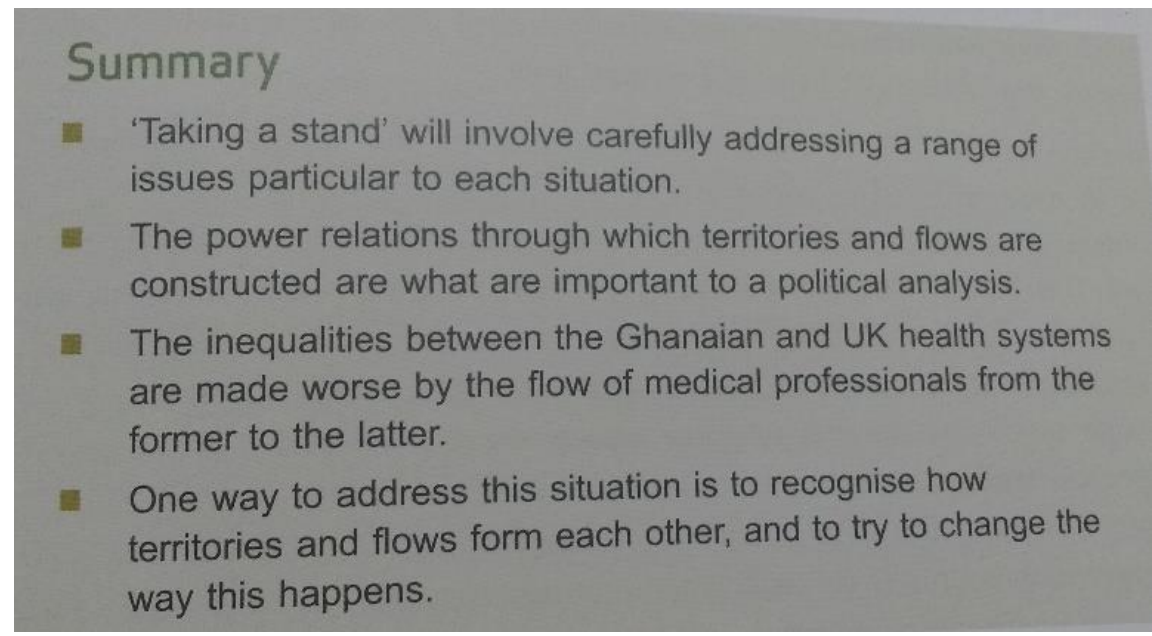

\section{Figura 3: Boxe de síntese de conteúdos (2008:333).}

Como dito anteriormente, uma das características do gênero textual do livro didático (e que é 
enaltecida na modalidade de educação a distância é a interatividade) é a busca pelo diálogo com o leitor. A narrativa central de Massey foca na América Latina para explicar o conceito da solidariedade e da responsabilidade em contraposição aos fatores da globalização financeira. 0 argumento de Massey recupera elementos dos conteúdos dos capítulos anteriores. Isto é, o capítulo de Massey valoriza a revisão de conteúdos. Mas, tal operação didática está a favor do desenvolvimento teórico, ou seja, de sua crítica ao que chamou de localismo, a fim de desconstruir uma polaridade entre lugar e globalização.

Além dos conceitos de fluxo e território, a discussão empreendida por Massey sobre as geografias das solidariedades se fundamenta também na apreensão dos conceitos de "poder" e de "responsabilidade" (2008:323). Convém, por exemplo, a análise de um exercício: "Use o argumento que foi feito até agora para dizer por que a mudança de coisas pode ser vista de forma tão impressionante. Tente encontrar uma série de razões distintas para fundamentar sua explicação " (idem).

Em outros artigos e ensaios teóricos, Massey reinterpreta a filosofia de Spinoza, especialmente, o conceito de responsabilidade. Importante destacar que não se restringe à visão liberal. Massey articula tal compreensão para questionar uma perspectiva de geografias das solidariedades, em particular, o debate sobre a migração dos profissionais da saúde de países periféricos da África e da Ásia para o Norte Global. No desenvolvimento da análise, ela provoca seu leitor: "Então, esses profissionais de saúde devem ser impedidos de migrar?" (2008:328).

Ela põe em questionamento percepções do senso comum. Nesse momento, ela interpela novamente o leitor para avaliar a complexidade das relações espaciais, recuperando o debate sobre "sentido global de lugar". Nessa direção, a autora oferece elementos ao seu interlocutor para observar os limites cognitivos e práticos de antagonizar o território ao fluxo: "[Com o argumento] colocado dessa maneira, nós reduziríamos o debate à sentença de o território versus o fluxo, mas nosso ponto de partida é outro". (2008:328).

Massey, nessa narrativa didática, identificou o imperativo da solidariedade internacional, na prática dos significados desse tipo de relação escalar. Mais além, ela desdobra seu argumento para o que chamou de "uma particular imaginação geográfica da solidariedade" (2008: 334).

Com a discussão de direitos autorais, por exemplo, Massey interpela seu leitor à complexidade da contingência política e das contradições nas ações solidárias. Para tanto, ela recupera a discussão da mídia independente e a sua emergência nos movimentos anticapitalistas. Aliás, ao selecionar os casos e os episódios e narrá-los, ela propõe uma interpretação das potências e dos limites da comunicação diante da dinâmica da geometria de poder. Com tal interpretação, Massey propõe a análise espacial articulando o debate entre a solidariedade, a responsabilidade e a comunicação. Tal associação é percebida por nós como potente conteúdo para o Ensino Médio, ainda pouco tratado sob a perspectiva geográfica. Pois, para ela os novos movimentos sociais e suas geografias e agendas dependem do fluxo de informação.

Nessa direção, é válida a análise sobre as contradições de movimentos localistas, como dos grupos do campesinato europeu que reivindicam mais barreiras e políticas antiglobais: "Considere a citação de Bové e Dufour (2001) acima. É realista? É mesmo democrática? E as afirmações que surgem em um mundo globalizado de uma conectividade mais ampla? E as pessoas "locais" que são ricas e poderosas? " (2008: 350)

0 foco central do capítulo está no desenvolvimento da ambiguidade e não da dicotomia entre conflito e solidariedade para interpretar e intervir no fenômeno espacial. Aqui ela recupera a discussão da desigualdade, pois o conflito poderia acionar um localismo conservador e se antagonizar às formas alternativas de coletividade, de solidariedade. 


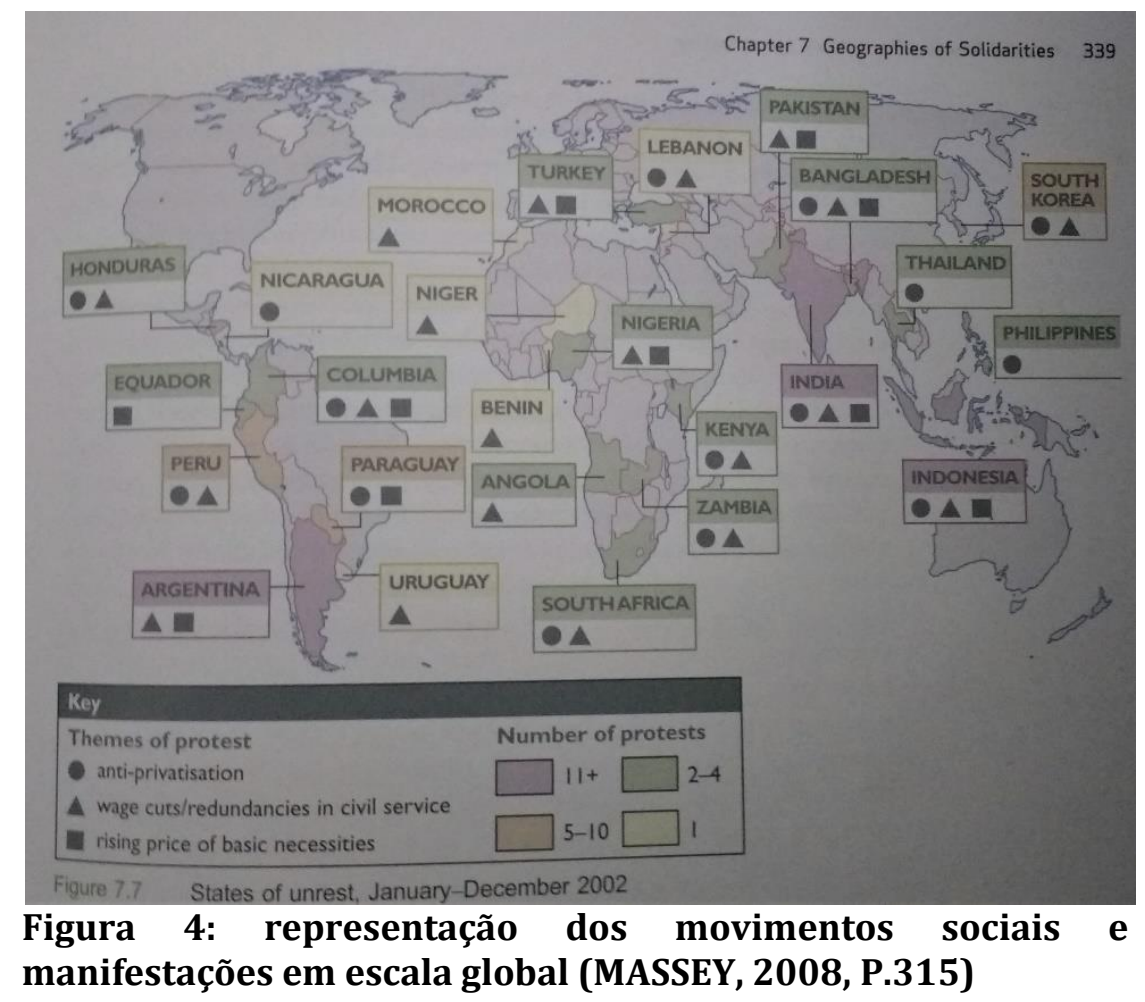

0 argumento é desenvolvido também pela linguagem não verbal, como a expressão de luta protagonizada pelas fotografias destacadas em meia página e com alta resolução dos movimentos sociais na América Latina. Outro exemplo é a cartografia temática adotada, oferecendo dados sobre as causas dos movimentos sociais anticapitalistas. Em linhas gerais, Massey, no decorrer do seu texto sobre as Geografias das solidariedades, experimenta operações pedagógicas para provocar o seu leitor a pensar sobre espaço, responsabilidade e geometria do poder.

\title{
3. Um encontro entre Doreen e Paulo: o porquê do encontro como ato pedagógico
}

\author{
Nalgum lugar faz-se esse homem... \\ Contra a vontade dos pais ele nasce, \\ contra a astúcia da medicina ele cresce, \\ e ama, contra a amargura da política. \\ (Contemplação no Banco, Carlos Drummond de Andrade)
}

A educação é um ato de amor, por isso, um ato de coragem. Não pode temer o debate. A análise da realidade. Não pode fugir à discussão criadora, sob pena de ser uma farsa.

(Paulo Freire, 1967)

É oportuno afirmar que a "palavra geradora1" na pedagogia de Doreen é o encontro. A sua concepção de espaço permite inferir que a representação (métrica) não esgota a explicação da geografia dos homens e das mulheres. Ao propor uma dimensão que associe o espaço ao tempo na busca do encontro, Doreen privilegia o movimento ao invés do retrato. Com esse princípio do espaço, como o olhar com-sobre-do-e- a partir do Outro, Massey vislumbra um método de apreensão e de aprender a Geografia.

Aqui revela-se o diálogo (imaginado) entre Doreen Massey e Paulo Freire: explicar a vida não se separa do viver. 0 método freiriano se baseia na indissociabilidade entre alfabetização e

${ }^{1}$ Aqui nos referimos à metodologia de letramento e de educação popular freiriana, com base na palavra geradora, considerando a experiência dos sujeitos políticos no processo de aprendizagem. 
conscientização. Massey induz seus leitores à uma filosofia do espaço que impede reducionismos e se filie à multiplicidade. Por isso, que ao unir Paulo Freire e Doreen Massey na análise de suas geografias solidárias, começamos com os versos de Drummond, porque a humanização é resistência das amarguras da política, "nalgum lugar faz-se esse homem", e no lugar onde aprender é como, diz Freire, aprender-se.

Se as geografias propostas por Massey trazem os espaços de resistência e da solidariedade, a pedagogia de Freire é voltada para os homens livres. O espaço de Doreen Massey é a prática de liberdade, porque é interdependente, se articula ao múltiplo e ao coetâneo. Assim como em Paulo Freire, a escrita de Doreen Massey funde a teoria à denúncia. A escrita pedagógica de Doreen Massey resulta da fusão entre o rigor teórico, uma proposta de diálogo e a crítica social. É uma escrita que não abandona a experiência do outro no projeto de aprender o espaço.

No artigo "The Geographical Mind", escrito e dedicado exclusivamente aos professores, Doreen Massey (2006) identifica três princípios que mobilizam e sustentam a vitalidade (curricular e política) do ensino da Geografia. Comecemos pela "Geografia pode ajudar aos jovens explorarem a contestada natureza do mundo" (2006:49). Para Massey, a potencialidade da Geografia - enquanto disciplina escolar - é oferecer aos jovens o ato de pensar geograficamente sobre os povos e sobre os lugares e, principalmente, rever suas próprias perspectivas a partir da lógica do Outro. Ao considerar as geometrias de poder, os estudantes são capazes de compreender as relações desiguais em que o mundo é construído e rever suas formas de pensar o mundo, reposicionar suas afirmativas. Com isso, a autora positiva o ensino de Geografia para a formação cidadã.

O segundo princípio elencado por Massey questiona o senso comum, "Muito da nossa geografia está na mente - das imagens mentais que concebemos o mundo" (2006: 50). A sua proposta de dimensionar os novos movimentos sociais na América Latina é um ato pedagógico de interrogar as imagens mentais mais difundidas sobre a região. As análises propostas a partir do estudo de caso recuperam uma interpretação didática de Geografias da responsabilidade, outro texto de sua autoria que sublinha a centralidade da política para a concepção de espaço.

Como terceiro princípio, Massey identifica que a "Geografia deveria auxiliar os estudantes como os lugares são diversos e complexos". Aqui novamente Doreen Massey aprecia os matizes e as intencionalidades da educação geográfica, uma abordagem próxima, isto é, muito similar, ao modelo cognitivo projetado por Paulo Freire, nos seus seminais trabalhos sobre educação popular, como em "A Educação como prática da liberdade" (FREIRE, 1967). A conscientização política é o foco em ambos.

As imaginações geográficas tratadas pela "Geografias das solidariedades" propostas por Massey acumulam proposições da conscientização política, induzem uma interpretação da agenda de resistência em escala global e local. Tal consideração dialoga com a seguinte afirmativa de Paulo Freire, registrada no seu exílio no Chile:

A partir das relações do homem com a realidade, resultantes de estar com ela e de estar nela, pelos atos de criação, recriação e decisão, vai ele dinamizando o seu mundo. Vai dominando a realidade. Vai humanizando-a. Vai acrescentando a ela algo de que ele mesmo é o fazedor. Vai temporalizando os espaços geográficos. Faz cultura. E é ainda o jogo destas relações do homem com o mundo e do homem com os homens, desafiado e respondendo ao desafio, alterando, criando, que não permite a imobilidade, a não ser em ternos de relativa preponderância, nem das sociedades nem das culturas. E, na medida em que cria, recria e decide, vão se conformando as épocas históricas. É também criando, recriando e decidindo que o homem deve participar destas épocas. (1967:43).

A multiplicidade como natureza do espaço é acionada também por Paulo Freire em todas as etapas do seu método. A identificação do sujeito com a realidade pauta as palavras geradoras, pauta, isto é, o seu processo educacional.

As imaginações geográficas do capítulo em tela emergem de uma relação produtora de identidade e de responsabilidade política. 0 debate do seu artigo Geografias das responsabilidades (MASSEY, 2004 A) está implícito na apreciação da autora no referido capítulo. As lutas sobre o lugar e sobre significar o lugar estão igualmente implicadas no texto.

Convém esclarecer como ela concebe "responsabilidade": "Responsabilidade, em outras

ParaOnde!?, Porto Alegre, v.10, n.2, p.85-95, 2018. Edição Especial com artigos publicados originalmente na XII ENANPEGE http://seer.ufrgs.br/paraonde 
palavras, deriva das relações através das quais a identidade é construída" (2004 a: 11). Massey conduziu essa discussão em diferentes trabalhos e reinterpreta teóricas feministas para evidenciar a responsabilidade como noção relacional entre a entidade (grupo, identidade, agência) e a construção da agenda política no espaço. De acordo com os seus escritos, há uma estreita relação entre responsabilidade política e o lugar. Para tanto, as operações didáticas do capítulo se detém na interpretação da responsabilidade sobre as relações de poder na configuração espacial. Aqui reside, novamente, uma fértil aproximação entre Paulo Freire e Doreen Massey: a construção de demandas políticas, considerando a sua geografia. Nessa direção, convém cotejarmos esse argumento com outra afirmativa de Paulo Freire:

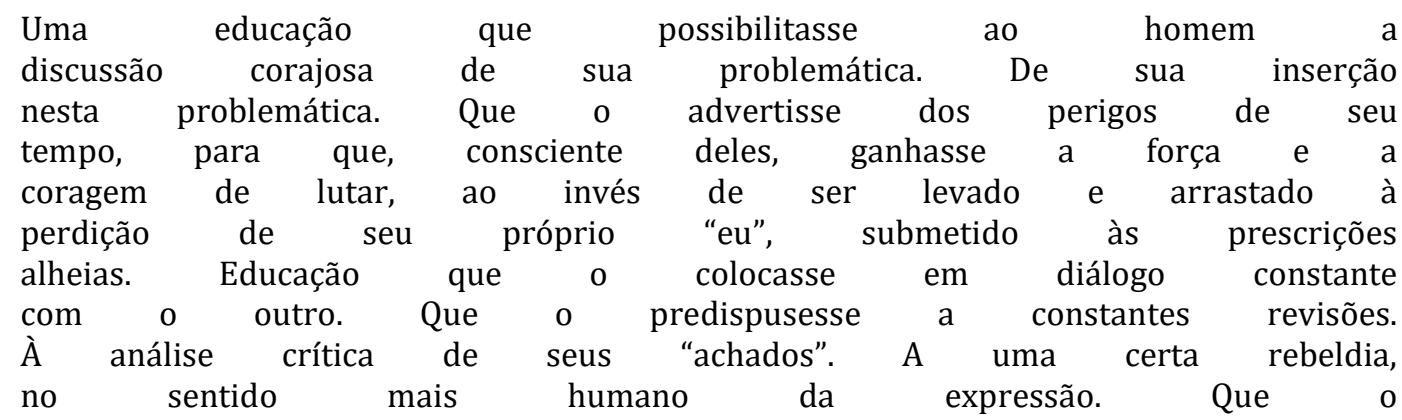

Nessa afirmativa, extraída de seu argumento sobre a "educação" versus "massificação", identificamos a centralidade da experiência, como método e a recusa das prescrições "alheias". Outro elemento que se tangencia com a proposição de Massey em seu livro didático, uma vez que sua interação com o leitor prima pela dialogicidade, pela lógica do Outro. Ao fazê-lo, Massey não se restringe à abordagem teórica. Ao contrário, a partir do estudo de caso, reiteração e interrogação, ela associa elementos epistemológicos da Geografia à retórica didática. 0 que potencializa a interpretação do espaço.

Em linhas gerais, a proposta pedagógica de Doreen Massey traduz a potência política da aprendizagem espacial, nas imaginações geográficas. A autora confere importância às agendas locais e às políticas em relação à globalização, ao selecionar recursos imagéticos e textos complementares para a razão pedagógica do capítulo. Logo, ela articula argumentos e recursos para sustentar a reflexão sobre as geografias da responsabilidade, o que Paulo Freire nomearia como "educação corajosa".

\section{Considerações finais: Massey e a pauta curricular hoje}

A educação das massas se faz, assim, algo de absolutamente fundamental entre nós. Educação que, desvestida da roupagem alienada e alienante, seja uma força de mudança e de libertação. (Paulo Freire, 1967, p. 34)

Este artigo procurou delinear uma via para o ensino de Geografia, considerando a contribuição de Massey para um material pedagógico. Ali, a teórica mesclou filosofia e compromisso político para interpretar a relação entre o espaço e o poder. Não por acaso, nossa interpretação dos recursos e operações didáticas prestigiadas por Massey nos leva a aproximá-la à "uma educação para $a$ decisão, para a responsabilidade social $e$ política" (FREIRE, 1967, P. 88).

A interpretação do espaço, do sujeito e da política é central no texto das Geografias das Solidariedades, inserida numa coleção de EAD que problematiza a dinâmica sociedade e natureza. 0 compromisso de Doreen Massey com a formação política se reproduz nos demais capítulos, mas nesse especificamente ela traz recursos didáticos e opera com a metodologia do estudo de caso para problematizar a responsabilidade e a agenda política local para problematizar a natureza desigual da globalização.

O livro em questão é editado e publicado em meio à crise econômica na Europa, que acentuou o 
desgaste da democracia representativa, haja visto o aprofundamento da vulnerabilidade social. Para tanto, o contexto daquela publicação também traz tinturas da urgência da temática abordada e das intencionalidades de apreciar agendas alternativas.

A análise deste material, por ora, ganha nova importância em função do contexto instável da política brasileira, que acelera as reformas de supressão de direitos civis. Os escândalos descarrilam o país e reposicionam a pauta educacional, o que nos leva ao compromisso em garantir princípios de liberdade e de luta, em particular, na defesa da disciplina no currículo escolar. Doreen Massey ao focar nas agendas dos novos movimentos sociais e chamando-as de geografias das solidariedades e as didatizando, nos oferece uma oportuna via da educação corajosa.

\section{Referências Bibliográficas}

ALBULQUERQUE, M.R. \& SILVA, I.M. Materiais didáticos impressos para educação a distância: interfaces com práticas de linguagens. IN: Educação Temática Digital, Campinas, vol. 14, n. 2, pp. 75-93, jul. dez. 2012.

CLARK, Nigel; MASSEY, Doreen; SARRE, Philip. Material Geographies - a world in the Making. SAGE Publications Inc., Milton Keynes/UK, 2008.

FREIRE, Paulo. Educação como prática de liberdade. Paz e Terra, Rio de Janeiro, 1967, 123p.

GABRIEL, Carmen Teresa. Currículo de História: entre experiências temporais e espaciais. Trabalho encomendado. In: VIII Encontro Nacional Perspectivas do Ensino de História e III Encontro Internacional de Ensino de História, 2012, p. 1-17 (no prelo).

- Currículo e epistemologia: sobre fronteiras do conhecimento escolar. Mesa redonda realizada no IX Colóquio sobre questões curriculares - V Colóquio Luso Brasileiro: Debater o Currículo e seus Campos, Políticas, Fundamentos e Práticas. Porto. 2010b.

HAESBAERT, R. Territórios Alternativas. Editora Contexto, 2ª.ed., São Paulo, 2006.

HAESBAERT, R. Regional - Global - Dilemas da Região e da Regionalização na Geografia Contemporânea. Bertrand do Brasil, Rio de Janeiro, 2010.

Território e multiterritorialidade: um debate. Geographia/UFF, n.17, Niterói, 2007, pp. 19-46.

HOLLMAN, V. , LOIS, C. Geo-grafías - Imágenes e instrucción visual em la geografía escolar. Paidós Cuestiones de Educación. Buenos Aires, 2015.

MASSEY, D. Pelo espaço - uma nova política da espacialidade. Bertrand do Brasil Editora, Rio de Janeiro, 2008.

.Massey, D. (2006) The geographical mind. In: Balderstone, D. (ed) Secondary Geography

Handbook, Sheffield, Geographical Association. Disponível
em:http://www.geography.org.uk/projects/valuingplaces/. Acesso: março de 2015.

. Filosofia e política da espacialidade: algumas considerações. Geographia - Ano 6, no. 12, Niterói, UFF, 2004, PP.7-23.

(A). Geographies of responsibility. IN: Geographiska Annaler - Serie B Human Geography. Volume 86, Issue 1, March 2004, Pages 5-18. Disponíel em:

http://oro.open.ac.uk/7224/1/Geographies of responsibility Sept03.pdf. Acesso em: março de 2017.

ParaOnde!?, Porto Alegre, v.10, n.2, p.85-95, 2018. Edição Especial com artigos publicados originalmente na XII ENANPEGE http://seer.ufrgs.br/paraonde 
MENDONÇA, D. \& RODRIGUES, L.P. Pós-estruturlismo e teoria do discurso: em torno de Ernesto Laclau. EDIPUCRS, Porto Alegre, 2008.

ROCHA, A.A. Questionando o questionário: uma análise do currículo e sentidos de Geografia no ENEM. Tese (Doutorado em Educação). 323 f. Universidade Federal do Rio de Janeiro, Rio de Janeiro, 2013. 